\title{
Assessment of sulfonation in lignocellulosic derived material for adsorption of methylene blue
}

\author{
Hee-Jeong Choi ${ }^{\dagger}$ \\ Department of Biosystems and Convergence Engineering, Catholic Kwandong University, Republic of Korea
}

\begin{abstract}
The lignocellulosic derived cornstalk was sulfonated (SCS) to prepare an adsorbent, and cationic dye methylene blue (MB) was adsorbed using SCS to evaluate its usability. Sulfonation improved the number of carboxyl groups $(-\mathrm{COOH})$ and increased the porosity and surface area of carbon. In the adsorption process in which MB is adsorbed using SCS in aqueous solution, the sulfone group expanded the form of the sulfonated adsorbent to increase the exposure of anions (sulfonic-acid $\left(\mathrm{R}-\mathrm{SO}_{3} \mathrm{H}\right)$, carboxylic groups, and bonded $\mathrm{OH}$-group) to the surface. As a result, the adsorption efficiency of MB, a cationic dye for SCS, was improved. The results of kinetics, adsorption isotherm and thermodynamics were suitable for Pseudo-2nd-order and Langmuir, and the adsorption process was endothermic and spontaneous physical adsorption. The maximal adsorptions capacity with Langmuir model was found to be $504.3 \mathrm{mg} / \mathrm{g}$ at $293 \mathrm{~K}$. Sulfonation improved not only electrostatic interaction but also $\pi-\pi$ stacking in the adsorption process, which was very advantageous in adsorbing cationic dyes using lignocellulose-based adsorbents.
\end{abstract}

Keywords: Adsorption, Cationic dye, Cornstalks, Kinetic, lignocellulose, Sulfonation

\section{Introduction}

Dyeing wastewater discharging facilities in Korea account for only $3.6 \%$ of all wastewater discharging facilities, but dyeing wastewater discharge amounts to $22.2 \%$ of the total wastewater discharge [1]. Moreover, the load of organic matter discharged from dyeing wastewater reaches $24.3 \%$ of the total, and dyeing wastewater is classified as a representative polluted industry in terms of wastewater generation and characteristics of wastewater [1, 2]. Most of the dyes have a complex and stable structure such as an aromatic structure, so it is difficult to decompose by chemical, physical and biological treatment [3]. Therefore, when these dyes are discharged without treatment, not only causes aesthetic problems due to chromaticity, but also the dye interferes with the penetration of sunlight into the water surface, thereby inhibiting photochemical and biological activities of aquatic plants. In addition, dyes pose a potential threat to the assimilation of organisms as they have the potential to pollute groundwater.

Currently, there are several methods of treating dye wastewater such as ozone oxidation treatment, coagulation treatment, advanced oxidation (AOP), and biological treatment etc. The agglomeration process is effective for removing insoluble dyes such as disperse dyes, but is not effective for soluble dyes, has a large amount of sludge, and it is difficult to completely remove chromaticity in water $[4,5]$. In the case of ozone treatment, it is effective to remove almost all dyes except for disperse dyes, but ozone has a short half-life and has an economic problem that requires a high cost because ozone must be continuously supplied [1]. Most of the known dye removal processes have a low removal efficiency compared to the operating cost, and particularly removal efficiency for low concentration of dye is very low $[5,6]$. On the other hand, the adsorption method is known to be suitable for the removal of dye wastewater because it is simpler to operate than other processes and the cost to enter the process is low [7, 8]. Therefore, studies on removing various dyes using activated carbon have been conducted by many researchers. Activated carbon, which has been widely used as an adsorbent so far, is useful for removing various contaminants because of its relatively large specific surface area and porosity [8-10]. Recently, biomaterials containing lignocellulosic, for example wheat straw, rice hull, daily palm leaves, tea waste and cashew nut shell, etc., are used to adsorb dyeing wastewater and heavy metals. Many researchers conducted heavy metal removal experiments using unmodified natural ligno-cellulosic biomaterials, and reported many positive results $[4,7,8,11]$.
This is an Open Access article distributed under the terms of the Creative Commons Attribution Non-Commercial License (http://creativecommons.org/licenses/by-nc/3.0/) which permits unrestricted non-commercial use, distribution, and reproduction in any medium, provided the original work is properly cited.

Copyright (C) 2022 Korean Society of Environmental Engineers
Received January 15, 2021 Accepted May 13, 2021

${ }^{\dagger}$ Corresponding author

E-mail: hjchoi@cku.ac.kr

Tel: +8233 6497297 Fax: +8233 6477635

ORCID: 0000-0003-3370-4277 
However, the application of unmodified lignocellulose has significant disadvantages such as low adsorption capacity in aqueous solution and high release of soluble organic compounds [5, 12]. Accordingly, in recent years, there is an increasing tendency to modify lignocellulose-based biomaterials in order to improve the removal efficiency of heavy metals, remove soluble organic compounds, and remove dyes in aqueous solutions. Agricultural waste contains large amounts of lignocellulose [7]. Lignocellulose is a type of complex cellulose, a combination of cellulose, hemicellulose, and lignin, and is one of the most abundant biomass on the planet as a major structural component of woody/non-woody plants [13]. However, currently only about 5\% of lignocellulose is used [10].

Lignocellulose has a three-dimensional aromatic structure and, when modified, has high reactivity, so a lot of interest has been focused on lignocellulose-based adsorbents [11, 12]. There are typically physical and chemical transformations in the modification method of lignocellulose. The physical modification is generally simple and inexpensive, but it is not widely used because of its low efficiency $[4,13]$. On the other hand, chemical modification has the advantage of being simple and highly efficient. In particular, several researchers have reported that sulfonation increases the adsorption efficiency of cationic heavy metals among chemical methods that can modify lignocellulose [14]. This is because pretreatment of lignocellulose using sulfonation leads to an increase in the negative charge, surface area and porosity of the biomass surface [10, 12]. Similarly, Elangovan et al. [15] reported that pretreatment of mangrove leaves and water lily leaves with sulfuric acid substantially improved the $\mathrm{Cr}(\mathrm{VI})$ adsorption capacity. In particular, CS is lignocellulose-based agricultural waste, which can be easily available material, and is very useful as a bio-adsorbent because of its high porosity. Therefore, this study attempted to sulfonate lignocellulose-based cornstalk to modify the surface with negative charges, and to use this to adsorb and remove methylene blue $(\mathrm{MB})$, which is the most widely used cationic dye, from aqueous solution.

\section{Material and Methods}

\subsection{Materials}

\subsubsection{Sulfonation of cornstalks}

Corn stalk (CS) was collected from a farmhouse in Gangneung, Korea. The CS was washed with tap water and then rinsed with distilled water to remove contaminants. The washed CS was cut into small pieces and dried in an oven at $85^{\circ} \mathrm{C}$ for $24 \mathrm{~h}$ to completely evaporate moisture. The dried CS was pulverized in a ball mill at $120 \mathrm{rpm}$ for $1 \mathrm{~h}$, separated into 40-60 mesh (0.25-0.4 mm) using an automatic sieve, and stored in a desiccator for use in experiments. A $20 \mathrm{~g}$ of CS powder was added to $60 \mathrm{~mL}$ of ethyl alcohol cooled to $-10^{\circ} \mathrm{C}$, mixed well, added to $200 \mathrm{~mL}$ of cooled sulfuric acid, and heated not to exceed to $10^{\circ} \mathrm{C}$ using a reaction device (Yhana (Model SS-200, 50W)). A sulfonation of cornstalk was performed while stirring at 100-150 rpm for $2 \mathrm{~d}$. After that, it was left at room temperature for 2 to $3 \mathrm{~h}$ to induce the reaction to occur completely, then washed several times with distilled water until neutral, and dried for $48 \mathrm{~h}$ in a dryer. The completed sulfonated corn stalk (SCS) were stored in a desiccator for use in experiments.

\subsubsection{Adsorbate}

MB (3,7-bis(Dimethylamino)-phenothiazin-5-ium chloride) used in the experiment is a basic cationic dye with the widest industrial application range among organic wastes and has a molecular weight of $319.85 \mathrm{~g} / \mathrm{mol}$. $\mathrm{MB}\left(\mathrm{C}_{16} \mathrm{H}_{18} \mathrm{~N}_{3} \mathrm{SCI}\right)$ is a heterocyclic aromatic chemical compound that exists in a very stable structure in aqueous solution, and when dissolved in a solvent, it is ionized to form $\mathrm{C}_{16} \mathrm{H}_{18} \mathrm{~N}_{3} \mathrm{~S}^{+}$and $\mathrm{Cl}^{-}$. It has a dark blue green color at room temperature, and exists in the form of three water molecules bound per molecule. MB was used by diluting the product of Tera Pharmaceuticals Inc, Buena Park, USA.

\subsection{Experimental Design}

In the MB adsorption experiment using SCS, a stock solution of $1,000 \mathrm{mg} / \mathrm{L}$ was prepared and the concentration of the solution required for the experiment was diluted and used. The experiment was carried out in the form of batch-test. Various amounts (0-20 $\mathrm{g} / \mathrm{L}$ ) of SCS were added to $1 \mathrm{~L}$ of dyeing water according to the experimental plan, stirred at $120 \mathrm{rpm}$, and then sampled at a predetermined time $(0,10,20,30,60,120$ and $240 \mathrm{~min})$. To determine the effect of $\mathrm{pH}$ on adsorption efficiency, the $\mathrm{pH}$ was adjusted to 2-10 using $\mathrm{HCl}$ and $\mathrm{NaOH}$. The influence on the temperature was controlled in the range of $10^{\circ} \mathrm{C}$ to $30^{\circ} \mathrm{C}$, and the parameters were changed, and the sample was taken at a predetermined time while stirring at $120 \mathrm{rpm}$ in a shaking incubator.

Adsorption kinetic studies were conducted various contact time (0-480 min) with different concentration of MB (Co: 20-1,000 mg/L), where the MB concentration was determined using a spectrophotometer (Shimadzu, MINI-1240). Equilibrium isothermal studies were determined at $303 \mathrm{~K}$ by using different $\mathrm{MB}$ concentration (20-1,000 mg/L), constant SCS dosage (1 g/L) and $\mathrm{pH} 7 \pm 0.3$ for $\mathrm{MB}$ solution. Similar procedure was adopted at the temperature 298-323K, where the other reaction parameters were held constant to study the thermodynamic parameters. For the adsorption kinetics, SCS was mixed with various concentration of MB and then shaken until equilibrium was sufficiently reached. Isothermal adsorption were analyzed using Langmuir, Freundlich and Temkin, and adsorption kinetics were interpreted using Pseudo-first-order, Pseudo-second-order and intraparticle diffusion. Thermodynamic analysis was performed using Gibbs' free energy.

\subsection{Analysis Methods}

Qualitative and quantitative analysis of inorganic components contained in SCS was analyzed using X-ray diffraction (XRD, XRF-1500, Shimadzu, Japan). The specific surface area, pore volume and average pore diameter of SCS were analyzed using a Brunauer-Emmett-Teller (BET) specific surface measuring machine (Model ASAP, 2020), and the molecular structure and composition of the surface functional groups were analyzed using Fourier-transform infrared spectroscopy (FT-IR, Jasco, FT-IR 4100). The size of the SCS particles was measured using a particle size analyzer (Laser Diffraction Master class 3\&4, Malvern, England), and the amount of SCS was measured with an electronic balance (XP26, 
Mettler Toledo, Swiss). The $\mathrm{pH}$ and temperature were measured using a pH meter (SevenGO pro, Mettler Toledo). The collected sample was measured using a UV-vis spectrophotometer (Shimadzu, MINI-1240) at $664 \mathrm{~nm}$, which is the maximum absorption wavelength of $\mathrm{MB}$, and the adsorption amount was calculated using Eq. (1).

$$
q_{t}=\frac{\left(C_{0}-C_{t}\right) V}{M}
$$

Where $C_{0}$ is the initial concentration (mg/L), $C_{t}$ is the concentration at time $\mathrm{t}, \mathrm{V}$ is the volume of $\mathrm{MB}$ solution (L), and $M$ is the amount of SCS (g). The $\mathrm{pH}_{\mathrm{pzc}}$ was analyzed according to the method reported in a previously published study [16]. All experiments were repeated five times and the average value was used as the experimental result. In order to experiment with one parameter, the other parameter was fixed.

To measure the ion exchange capacity (IEC), chemically treated SCS should be hydrogenated. Generally, a conventional acid-base titration method is used to determine the IEC [17]. The IEC was calculated according to the general Eq. (2).

$$
\operatorname{IEC}(\mathrm{meq} / \mathrm{g})=\frac{V_{\mathrm{NaOH}} N_{\mathrm{NaOH}}-V_{\mathrm{HCl}} N_{\mathrm{HCl}}}{\text { Weight of dried sample }}
$$

where, $\mathrm{V}_{\mathrm{HCl}}$ was the volume of $\mathrm{HCl}$ entered during quantification in $\mathrm{mL}, \mathrm{V}_{\mathrm{NaOH}}$ was the volume of $\mathrm{NaOH}$ used, and $\mathrm{N}_{\mathrm{HCl}}$ and $\mathrm{N}_{\mathrm{NaOH}}$ is the normal concentration of $\mathrm{HCl}$ and $\mathrm{NaOH}$ used, respectively. Resin weight refers to the total weight and $0.2 \mathrm{~g}$ of ion exchange resin was obtained by measuring the weight of the resin dried at $110^{\circ} \mathrm{C}$ for one day.

To select appropriate kinetic and isotherm models for MB adsorption process, Chi-squre $\left(\chi^{2}\right)$ was calaulated using Eq. (3).

$$
\chi^{2}=\sum_{i=1}^{n} \frac{\left(q_{e, e x p}-q_{e, c a l}\right) 2}{q_{e, c a l}}
$$

where $q_{e, e x p}$ and $q_{e, c a l}$ are equilibrium adsorption capacity obtained from experiments and models, respectively.

\section{Results and Discussion}

\subsection{Charateristic of SCS}

\subsubsection{Physical property}

The results of component analysis of CS and SCS are summarized in Table 1. The major constituents of CS and SCS were carbon and oxygen, and in addition they contained small amounts of hydrogen and nitrogen. After sulfonation of CS, the content of oxygen increased and the content of carbon decreased. This may be due to the release of volatiles during the sulfonation process, and the relatively high oxygen content is believed to be due to the high level of chemical active agent used $\left(\mathrm{H}_{2} \mathrm{SO}_{4}\right.$; 95-98\%). As the $\mathrm{H} / \mathrm{C}$ ratio approaches 1 , the aromaticity of the bio-adsorbent increases, and when the $\mathrm{O} / \mathrm{C}$ ratio is high, the anionic properties of the bio-adsorbent are strengthened due to the increase of the carboxylate group in the bio-adsorbent, thereby increasing the ability to adsorb cationic substances [1, 5]. After sulfonation the $\mathrm{H} / \mathrm{C}$ ratio improved from 0.04 to 0.14 , and the $\mathrm{O} / \mathrm{C}$ ratio increased from 0.65 to 1.27 , indicating that the carboxyl group inside the SCS adsorbent increased.

The BET surface area $\left(24.13 \mathrm{~m}^{2} / \mathrm{g}\right)$ of SCS increased by about 2.9-fold that of CS, and this increased specific surface area was thought to be due to the high concentration of $\mathrm{H}_{2} \mathrm{SO}_{4}$ that enhanced the pore volume and surface area. It was observed by previous studies that biomass results in a high specific surface area when treated with concentrated $\mathrm{H}_{2} \mathrm{SO}_{4}[18,19]$. It is difficult to establish the relationship of the interaction with the adsorption capacity with only the surface area of the adsorbent because there are many other factors that contribute to the efficiency of the adsorption process. However, many researchers emphasized that the adsorption of $\mathrm{MB}$ affects the surface acidity of carbon by various surface functional groups such as phenol and carboxyl groups due to the influence of electrostatic interactions with the adsorbent. It was confirmed by several researchers that such surface acidity affects the adsorption efficiency of $\mathrm{MB}[6,12,20-22]$.

Ion exchange capacity is one of the important properties of adsorbents. This is because the large ion exchange capacity means a large number of functional groups [17, 23]. The ion exchange capacity of SCS was measured about 2.53-fold higher than that of CS, indicating $4.13 \mathrm{meq} / \mathrm{g}$. In general, the higher the ion exchange capacity, the higher the adsorbed amount of metal [7]. Also, the size of the pores of the adsorbent may affect the adsorption efficiency [11]. Benadjemia et al. [24] reported the effect of adsorbent pore structure on the adsorption of MB. A high magnification SEM image of CS and SCS samples (Fig. S1) revealed that the surface became rougher and more porosity after sulfonation. According to the study, MB molecules could not pass through pores of less than $1.0 \mathrm{~nm}$ (super-micropores), and adsorbents having a pore structure of at least $1.33 \mathrm{~nm}$ in diameter had higher $\mathrm{MB}$ adsorption capacity than those of micropores $(<2 \mathrm{~nm})$ or macros $(>30 \mathrm{~nm})$. The pore size of SCS increased from $1.135 \mathrm{~nm}$ of CS to 3.215 $\mathrm{nm}$, which is within the range of micro-meso pore structure. After

\begin{tabular}{|c|c|c|c|}
\hline \multicolumn{2}{|l|}{ Component (mass \%) } & CS & SCS \\
\hline \multicolumn{2}{|l|}{$\mathrm{O}$} & 36.23 & 52.48 \\
\hline \multicolumn{2}{|l|}{$\mathrm{C}$} & 55.42 & 41.24 \\
\hline \multicolumn{2}{|l|}{$\mathrm{H}$} & 2.33 & 5.76 \\
\hline \multicolumn{2}{|l|}{$\mathrm{N}$} & 1.53 & 1.61 \\
\hline \multicolumn{2}{|l|}{ S } & - & 1.32 \\
\hline \multicolumn{2}{|l|}{$\mathrm{Mg}$} & 0.09 & 0.10 \\
\hline \multicolumn{4}{|l|}{ Surface property } \\
\hline \multicolumn{2}{|l|}{ Pore volume $\left(\mathrm{cm}^{3} / \mathrm{g}\right)$} & 0.102 & 0.164 \\
\hline \multirow{3}{*}{ Pore diameter (nm) } & $<2 \mathrm{~nm}$ & 95.4 & \\
\hline & $2-30 \mathrm{~nm}$ & 4.6 & 96.8 \\
\hline & $>30 \mathrm{~nm}$ & - & 3.2 \\
\hline \multicolumn{2}{|c|}{ BET surface area $\left(\mathrm{m}^{2} / \mathrm{g}\right)$} & 8.32 & 24.23 \\
\hline \multicolumn{2}{|c|}{ Ion exchange capacity (meq/g) } & 1.63 & 4.13 \\
\hline
\end{tabular}
sulfonation of CS, the amount of mesopores increased and decreased

Table 1. Characteristic of CS and SCS (unit: \%)

micropores. In particular the increase of mesoporous amount in 
SCS samples (96.4\%) is benefical for enhancing adsorption of $\mathrm{MB}$ performance.

\subsection{2. $\mathrm{pHpzc}$}

The pHpzc (point of zero charge) is the $\mathrm{pH}$ at which the net charge on the surface of the adsorbent becomes zero [25]. The pHpzc is important because the adsorption of some substances depends on the $\mathrm{pH}$ of the aqueous solution, and the pzc value is determined by the properties of the adsorbent [1]. From the point of view of the adsorbent, if the $\mathrm{pH}$ is lower than the pzc value, the surface charge of the adsorbent becomes positive and anions may be adsorbed. On the contrary, if the $\mathrm{pH}$ is higher than the pzc value, the surface charge becomes negative, so that cations may be adsorbed. To find the surface charge of SCS, the experiment was conducted by adjusting the $\mathrm{pH}$ to $3-10$, and the results are shown in Fig. 1. The $\Delta \mathrm{pH}$ is the value obtained by subtracting the initial $\mathrm{pH}$ from the final $\mathrm{pH}$. The $\mathrm{pHpzc}$ of SCS was found to be 5.3, and it was confirmed that there is an acidic functional group on the SCS surface. The negative surface charge of SCS can be found in a $\mathrm{pH}$ environment above pHpzc favoring the adsorption of $\mathrm{MB}$ cations. In general, the adsorption of $\mathrm{MB}$ may be due to the presence of $\mathrm{OH}, \mathrm{COO}-$, and $\mathrm{SO}_{3}^{-}$groups on the SCS surface. According to previous studies, the pHpzc values of coconut leaves and mango peels were 3.2 and 4.6, respectively, and were reported to be low after sulfonation with $\mathrm{H}_{2} \mathrm{SO}_{4}[26,27]$.

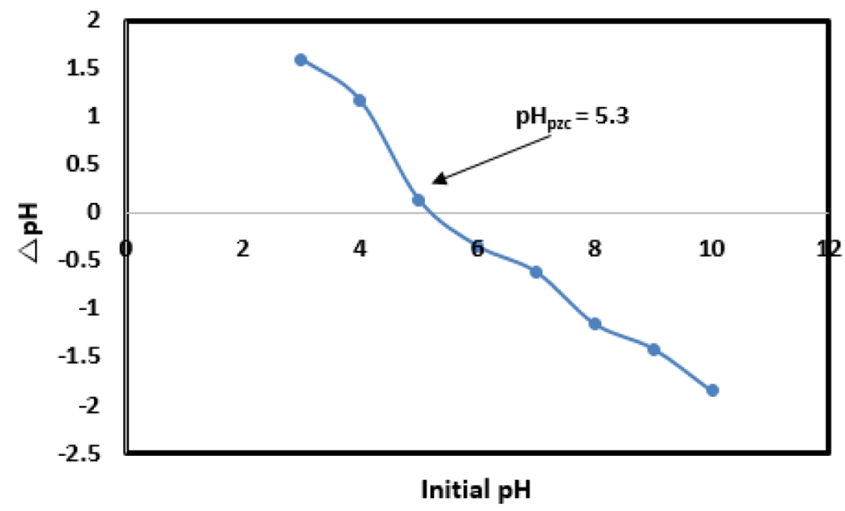

Fig. 1. pHpzc of SCS suspensions in aqueous solution at ambient conditions.

\subsubsection{FT-IR spectra}

$\mathrm{MB}$ is a cationic molecule containing 6 carbon aromatic rings, nitrogen and sulfur in its molecular structure that affects the interaction of the adsorbent with the carbon surface [22]. The process of adsorption of $\mathrm{MB}$ to carbon occurs through electrostatic interactions, formation of hydrogen bridges, electron donor acceptor relationships, and the electron dispersing force of $\pi$ - $\pi$ between functional groups on the carbon surface with $\mathrm{MB}$ molecules [5]. Therefore, in addition to the surface area and porosity of the carbon adsorbent, the presence of functional groups such as $-\mathrm{C}=\mathrm{O}$, -COC-, $-\mathrm{OH},-\mathrm{NH}_{2},-\mathrm{C}=\mathrm{S},-\mathrm{C}=\mathrm{N}$ and $-\mathrm{S}=\mathrm{O}$ on the carbon surface plays an important role in increasing the adsorption capacity to separate $\mathrm{MB}[1,9]$.

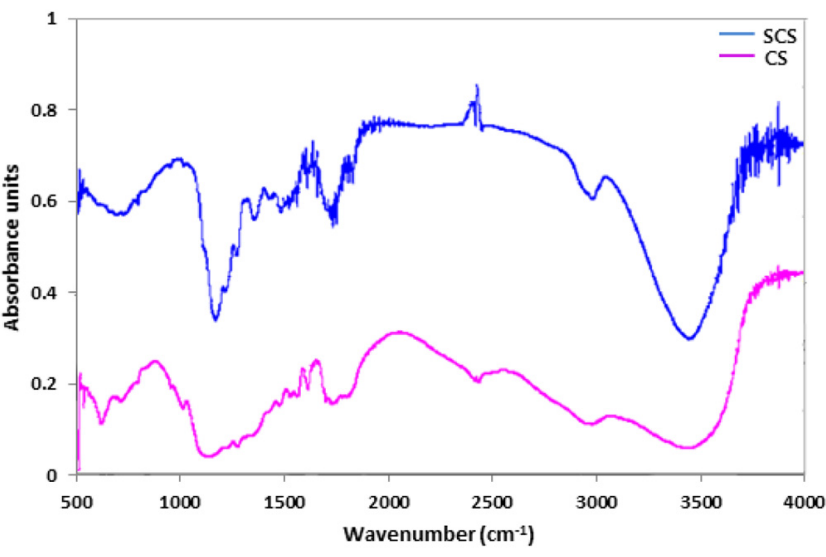

Fig. 2. A FT-IR spectra of CS and SCS.

FT-IT results of SCS were bonded OH-group (3,000-3,500 $\left.\mathrm{cm}^{-1}\right)$, $\mathrm{CH}$ stretching $\left(2,900-2,800 \mathrm{~cm}^{-1}\right), \mathrm{C}=\mathrm{O}$ cabonyl groups $(1,740-1,680$ $\left.\mathrm{cm}^{-1}\right)$, and carboxylic groups $\left(1,670-1,640 \mathrm{~cm}^{-1}\right)$, CO stretch (1,450-1,300 $\left.\mathrm{cm}^{-1}\right)$, C-O-C groups $\left(1,200-1,230 \mathrm{~cm}^{-1}\right), \quad \mathrm{SO}_{3} \mathrm{H}$ $\left(1,150-1,165 \mathrm{~cm}^{-1}\right)$ and $\mathrm{S}=\mathrm{O}$ groups $\left(1,010-1,040 \mathrm{~cm}^{-1}\right)$ peaks which appeared due to sulfonation (Fig. 2). In particular, the peak of 1,010-1,200 $\mathrm{cm}^{-1}$ increased significantly due to the introduction of sulfone groups. In addition, it was confirmed that the ether of $1,109 \mathrm{~cm}^{-1}$, the absorption peak of $\mathrm{R}-\mathrm{SO}_{3} \mathrm{H}$ of $1,232 \mathrm{~cm}^{-1}$, and ketone peaks of $1,642 \mathrm{~cm}^{-1}$ and $1,477 \mathrm{~cm}^{-1}$ were sulfonated. In

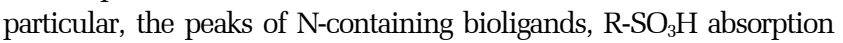
peak, carboxylic groups and bonded $\mathrm{OH}$-group were larger than that of CS, and there were more functional groups. This indicates that SCS has a structure that is easier to adsorb $\mathrm{MB}$ ions than CS. Osman et al. [28] reported that the adsorption capacity of metals is proportional to the number of functional groups in the adsorbent. It is believed that the change of functional groups through sulfonation will affect the adsorption

\subsection{Parametric Study}

\subsubsection{Dose of adsorbent}

Development of an environmentally friendly adsorbent capable of adsorbing a large amount of harmful substances inexpensively and in a small amount is advantageous in terms of economy, but is also required in terms of environment. To determine the effect of the amount of SCS on the adsorption efficiency of MB, experiments were performed the concentration of $\mathrm{MB}$ was increased from $0.1 \mathrm{~g} / \mathrm{L}$ to $1 \mathrm{~g} / \mathrm{L}$, around $\mathrm{pH} 7$ and $25^{\circ} \mathrm{C}$. The relationship between the $\mathrm{MB}$ removal efficiency of more than $90 \%$ and the amount of SCS is shown in Fig. S2, the correlation was 0.9982. As a result of calculating the amount of SCS required for MB removal with the correlation coefficient, the amount of about 19.5 mg of dye/g of SCS could be removed. When MB was removed using SCS, it is very economical because it uses lignocellulose derived agricultural by-products, which are discared wastes, so that the discarded resources can be reused. According to previous studies, when the adsorbent was sulfonated, the ion exchange capacity increased compared to the unmodified adsorbent, and accordingly, the removal efficiency of MB was improved [27, 29]. This is consistent with the research results of many researchers 
who adsorbed heavy metals in aqueous solutions by modifying agricultural waste as already mentioned in the introduction.

\subsubsection{Effect of $\mathrm{pH}$}

In aqueous solution, $\mathrm{pH}$ has a great influence on the adsorption process of organic and inorganic substances. To find out the effect of $\mathrm{pH}$ on the $\mathrm{MB}$ removal efficiency, the $\mathrm{pH}$ was tested in the range of 2-10 for $12 \mathrm{~h}$. The removal efficiency of MB using SCS was equilibrated in $3 \mathrm{~h}$ and was $10.65 \%$ at $\mathrm{pH} 2,28.64 \%$ at $\mathrm{pH}$ 4, 92.03\% at $\mathrm{pH} 6,96.01 \%$ at $\mathrm{pH}$ 8, and $97.62 \%$ at $\mathrm{pH} 10$ (Fig. 3). The higher the $\mathrm{pH}$, the higher the initial removal efficiency of the reaction, and above $\mathrm{pH} 6$ the $\mathrm{MB}$ removal efficiency was almost unchanged after $3 \mathrm{~h}$. In addition, it can be seen that $\mathrm{MB}$ exhibits high removal efficiency over $\mathrm{pH}$ 6, therefore it is better removed at higher $\mathrm{pH}$ than at lower $\mathrm{pH}$. This is related to the value of pHpzc mentioned above where the pHpzc of SCS was found to be 5.4. If the $\mathrm{pH}$ is higher than the pzc value, the surface charge of the adsorbent becomes negative, so that cationic ions are adsorbed well. In addition, as the $\mathrm{pH}$ increased, the removal efficiency of $\mathrm{MB}$ increased. This means that the sulfonic acid, carboxyl and phenolic hydroxyl groups of the SCS adsorbent were deprotonated as the $\mathrm{pH}$ increased to form $\mathrm{R}_{-} \mathrm{SO}_{3}{ }^{2-}, \mathrm{R}-\mathrm{COO}^{-}$and R-O- groups. As a result, the surface of the SCS adsorbent became negatively charged, and the electrostatic attraction between the SCS adsorbent and MB, which is a cationic dye in the aqueous solution, was improved. This opinion is also consistent with the reason why the adsorption efficiency increases with increasing $\mathrm{pH}$ as explained in the experiment of adsorbing cationic dyes using sulfonated lignin by $\mathrm{Li}$ et al. [27]. In general, as the $\mathrm{pH}$ of the solution increases, the adsorption efficiency of the cationic metal increases, while the removal efficiency of the anion metal decreases [25]. This is because at low $\mathrm{pH}, \mathrm{H}^{+}$ions compete with metal cations to reduce bioadsorbability. Conversely, as the $\mathrm{pH}$ value increases, the surface of the adsorbent gradually becomes negatively charged, and the absorption of metal ions is advantageous due to the electrostatic interaction. On the other hand, $\mathrm{MB}$ exists as cationic species and undissociated molecules in aqueous solutions. At $\mathrm{pH} 3$, undissociated molecules of $\mathrm{MB}$ dominate at $86 \%$, at $\mathrm{pH} 4$ cationic species and undissociated molecules exist at $50 \%$ each, and at $\mathrm{pH} 6$ or higher, only cationic species exist $[1,26]$. Thus, the high removal

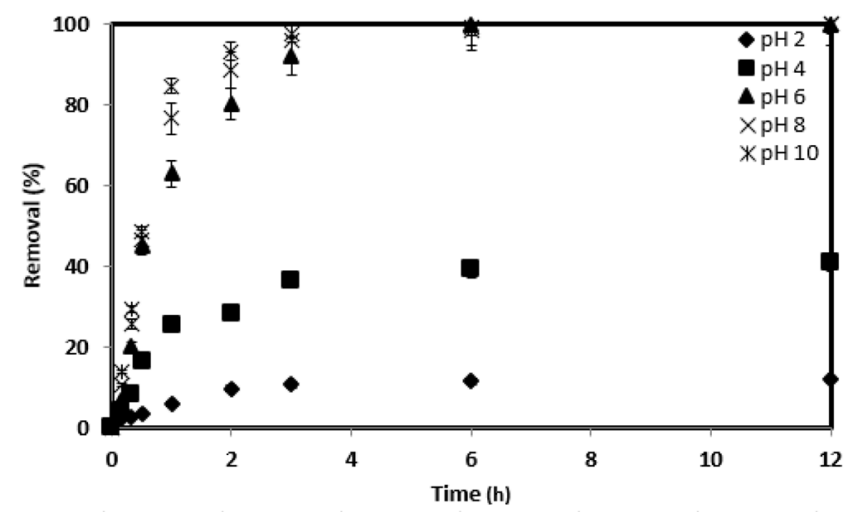

Fig. 3. Effect of $\mathrm{pH}$ on the adsorption of $\mathrm{MB}$ (SCS: $1 \mathrm{~g} / \mathrm{L}, \mathrm{MB}$ concentration: $10 \mathrm{mg} / \mathrm{L}$, agitation: $120 \mathrm{rpm}, \mathrm{T}: 25^{\circ} \mathrm{C}$ ). efficiency at a high $\mathrm{pH}$ is because anions in the aqueous solution increase as the $\mathrm{pH}$ increases, making it easier to adsorb $\mathrm{MB}$ present as a cationic species.

\subsection{Adsorption Kinetics and Adsorption Isotherm}

\subsubsection{Adsorption kinetics}

In order to examine the MB adsorption rate of SCS, adsorption kinetics were analyzed using pseudo-first order and pseudo-second order. Pseudo-first order depends on the concentration of only one reactant, that is, the monomolecular reaction [30]. Different reactants may be present in the aqueous solution, but each will be in zero order. Rodrigues and Silva [31] reported that the pseudo-first order of lagergreen is simple but theroretically inconsistent. Pseudo-second order depends on the concentration of one secondary reactant or two primary reactants [4]. Therefore, when analyzing the adsorption rate of various adsorbents in aqueous solution, it is often more suitable for pseudo-second order than pseudo-first order. The analysis results of adsorption kinetics are shown in Table 2 and Fig. S3. The correlation coefficient $\left(\mathrm{R}^{2}\right)$ of the kinetic model was measured higher in pseudo-2nd-order (0.9775) than pseudo-1st-order (0.7814). Beside the $\mathrm{q}_{\mathrm{cal}}$ calculated in the pseudo-2nd-order model was closer to the measured $\mathrm{q}_{\text {exp }}$ compared to the value calculated in the pseudo-1st-order model. Moreover, the value of $\chi^{2}$ in pseudo-2nd-order was lower (1.7231) than pseudo-1st-order (5.5846). Therefore, removal of MB from aqueous solution using SCS was more suitable for pseudo-2nd-order model than pseudo-1st-order.

Fig. S3(c) was applied to the internal particle diffusion model equation, and it was found that the data did not show a linear relationship and did not cross the origin. These results suggest that the process of adsorption of MB onto the SCS occurs through a complex mechanism through transfer of external substances and diffusion of internal particles [30]. Therefore, in the Fig. S3(c), mass transfer occurs in the initial area of adsorption $\left(t_{1 / 2}<1.7\right)$, and the adsorption process occurs due to diffusion of internal particles in the linear area after that $\left(\mathrm{t}_{1 / 2}>1.7\right)$. The internal particle diffusion rate constant of $\mathrm{MB}$ obtained from the slope of the linear equation was $48.55 \mathrm{mg} / \mathrm{g} \cdot \mathrm{h}_{0.5}$.

In the adsorption process, when the mixture of the solution and the adsorbent is not uniform, the concentration of the adsorbent is low, the particle size of the adsorbent is small, and the adsorbent has a high affinity with the adsorbent, the transfer of external substances determines the adsorption rate [3, 32]. On the other hand, when the mixture of the solution and the adsorbent is smooth, the particle size of the adsorbent is large, the concentration of the adsorbent is high, and the affinity between the adsorbent and the adsorbent is low, intraparticle diffusion is the rate determining step [12, 25]. In the internal particle diffusion model, the value of the constant $C$ representing the thickness of the boundary layer indicates whether adsorption is controlled only by internal diffusion [33]. If $C$ is zero, intraparticle diffusion is the only rate controlling step in the adsorption step, otherwise adsorption is determined by many rate control settings $[27,28]$. The intraparticle diffusion constant $C$ represents the intercept of the internal diffusion model linear equation, and the larger the $C$ value, the greater the influence of the boundary layer $[1,30]$. In the experiment, $C$ was measured 
Table 2. Kinetics and Isothermal Parameters for the Adsorption of MB onto SCS

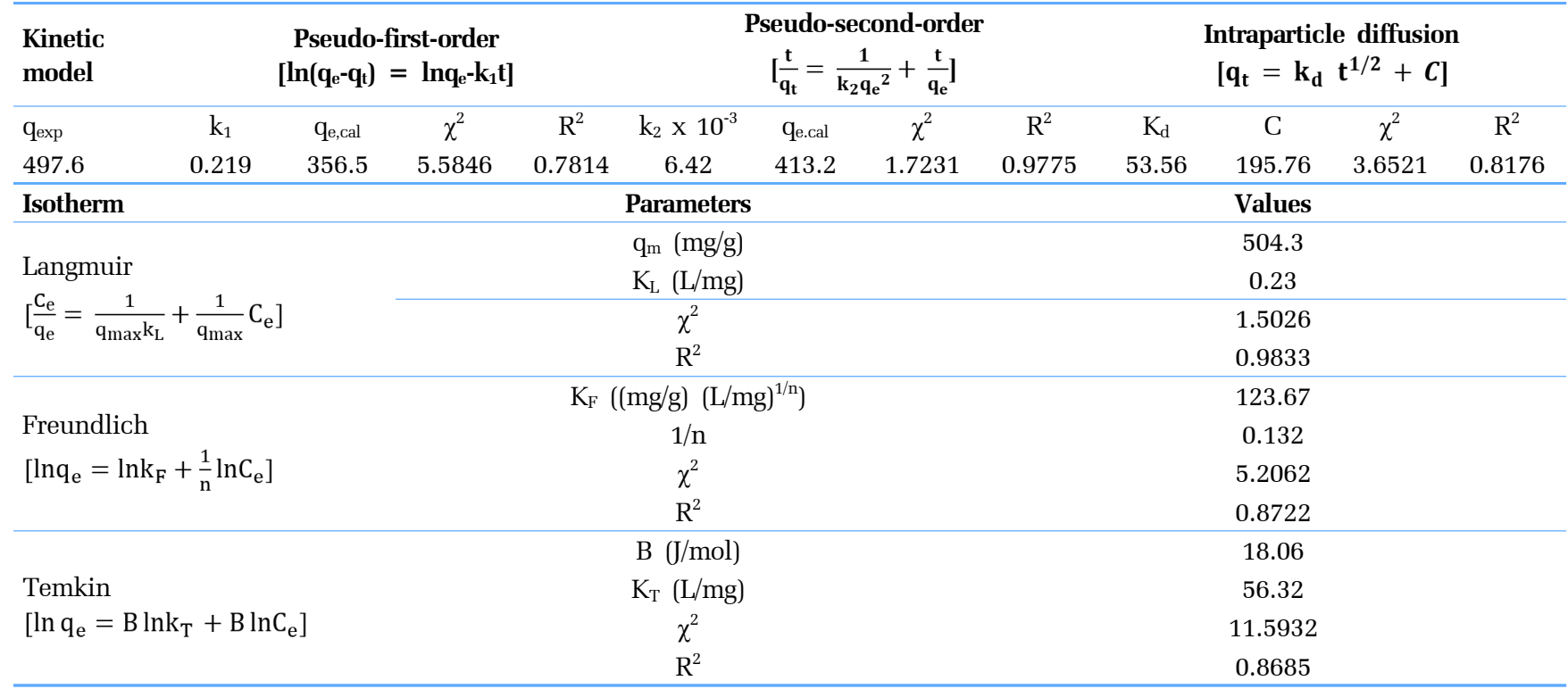

qe: adsorbed amount of MB at equilibrium (mg/g), q $\mathrm{q}_{\mathrm{t}}$ amounts of MB adsorbed by SCS at equilibrium time $\mathrm{t}$ (mg/g), $\mathrm{k}_{1}$ : Pseudo-1st-order constant (1/min), $\mathrm{k}_{2}$ : Pseudo-2nd-order constant (g/mg-min), t: time (min), $\mathrm{k}_{\mathrm{d}}$ : rate constant of intraparticle diffusion $\mathrm{kinetic}\left(\mathrm{mg} / \mathrm{g} \cdot \mathrm{h}_{0.5}\right.$ ), $C$ : constant associated with the boundary layer thickness. $\mathrm{C}_{\mathrm{e}}$ : $\mathrm{MB}$ concentration at equilibrium (mg/L), $\mathrm{q}_{\max }$ : Langmuir maximum adsorption capacity $(\mathrm{mg} / \mathrm{g}), \mathrm{K}_{\mathrm{L}}$ : Langmuir constant $(\mathrm{L} / \mathrm{mg}), \mathrm{K}_{\mathrm{F}}$ : adsorption capacity $(\mathrm{mg} / \mathrm{g})(\mathrm{L} / \mathrm{mg})^{1 / \mathrm{n}}, 1 / \mathrm{n}$ : adsorption intensity of the system, $\mathrm{k}_{\mathrm{T}}$ : Temkin isotherm constant $(\mathrm{L} / \mathrm{mg})$, B: correlated to adsorption heat

as 195.76, indicating that the adsorption of MB using SCS was not controlled only by internal diffusion, but the adsorption control was determined complexly by various factors.

\subsubsection{Isotherm modelling}

An isothermal adsorption experiment was performed to obtain information on the adsorption characteristics of MB on SCS, and the obtained results are analyzed and summarized in Table 2. In general, isothermal adsorption is analyzed using models of Langmuir, Freundlich and Temkin. The Langmuir isothermal adsorption equation is a model that assumes that each reaction site has a uniform reaction intensity [25, 28]. The Freundlich equation is an adsorption model under the assumption that the adsorption site of the adsorbent is not uniform and the adsorption energy continuously decreases as the adsorption amount increases [32]. The Temkin isotherm indicates that the heat of adsorption of $\mathrm{MB}$ molecules decreases linearly rather than logarithmically with coverage [34]. A linear plot of Langmuir, Freundlich and Temkin are in Fig. S4.

From the Langmuir equation, the dimensionless constant $\mathrm{R}_{\mathrm{L}}$ (= $1 /\left(1+K_{L} C_{0}\right)$, expressed as the separation factor or the equilibrium factor, can be calculated. The $\mathrm{R}_{\mathrm{L}}$ was found to be 0.037 , which corresponds to the range between 0 and 1 , and it was evaluated that it is suitable to adsorb MB using SCS. In addition, the maximum adsorption amount of Langmuir was $504.3 \mathrm{mg} / \mathrm{g}$, which was higher than that of walnut $(315.0 \mathrm{mg} / \mathrm{g})$, rice straw $(40.0 \mathrm{mg} / \mathrm{g})$, tea waste (85.2 mg/g), and white pine sawdust (102.0 mg/g) (Table 4). The Temkin isothermal adsorption constant $\mathrm{B}$ was measured to be 18.06 $(\mathrm{J} / \mathrm{mol})$, corresponding to the physical adsorption area $\mathrm{B}<20 \mathrm{~J} / \mathrm{mol}$. Therefore, the adsorption of MB onto SCS was closer to physical adsorption caused by the action of Van der Waals force consisting of dispersing and static power rather than chemical adsorption in which the chemical form of the adsorbed material is changed by the reaction between the adsorbent and the adsorbate.

The value of $K_{F}$, which is a measure of the adsorption capacity calculated from the Freundlich equation, indicates that the higher the value, the better the adsorption capacity. In this experiment, 1/n was analyzed to be 0.132 and the $K_{F}$ value was high, indicating that the adsorption of MB onto SCS occurs easily in aqueous solution and adsorption capacity was excellent. The applicability of the adsorption model was that Langmuir's correlation coefficient $\left(\mathrm{R}^{2}\right.$ $=0.9833)$ was higher than Freundlich's $\left(\mathrm{R}^{2}=0.8722\right)$ or Temkin's $\left(\mathrm{R}^{2}=0.8685\right)$, so the adsorption of MB onto SCS was considered to be more suitable for the Langmuir model.

Table 3 compares the maximum adsorption amount of $\mathrm{MB}$ using lignin or ligno-cellulose or cellulose-based agricultural by-products. Overall, the modified adsorbent had a higher maximum adsorption amount than the unmodified natural adsorbent, which provided a good reason to modify the adsorbent. The maximum adsorption amount of MB using SCS was $504.3 \mathrm{mg} / \mathrm{g}$, which was appropriately high compared to other adsorbents.

\subsection{Proposable Adsorption Mechanism}

SCS is a strong acid cation resin (SAC). According to the literature, SAC resin adsorbs almost all cations contained in the aqueous solution and exchanges them for hydrogen ions [39]. Since this ion exchange process is reversible, when the ion exchange capacity is exhausted, the resin can be regenerated using a strong acid. In addition, since the SAC resin is well applied in all $\mathrm{pH}$ ranges, 
Table 3. Comparison of the Maximum Adsorption Capacities of MB Dye onto Agricultural Waste Adsorbents

\begin{tabular}{|c|c|c|}
\hline Adsorbent & $q_{m}(\mathrm{mg} / \mathrm{g})$ & Reference \\
\hline Walnut shell & 315.0 & [35] \\
\hline White pine sawdust & 102.0 & {$[36]$} \\
\hline Rice straw & 40.0 & {$[37]$} \\
\hline Tea waste & 85.2 & {$[38]$} \\
\hline sulfonated lignin-based hydrogels & 540.5 & {$[27]$} \\
\hline lignin derived sulfonated porous carbon & 420.4 & {$[12]$} \\
\hline Carbonylated cellulose/ microfibrillated cellulose spheres & 303.0 & {$[2]$} \\
\hline Cellulose nanowhiskers based polyurethane foam & 554.8 & {$[3]$} \\
\hline Activated carbon nanotubes & 399.0 & {$[34]$} \\
\hline Acetic acid lignin & 63.3 & {$[21]$} \\
\hline sulfonated chitosan & 351.7 & {$[22]$} \\
\hline sulfonated corn stalk & 504.3 & This study \\
\hline
\end{tabular}

its application range is very wide [5]. Adsorption of $\mathrm{MB}$ in aqueous solution is highly dependent on the various polar functional groups on the surface [37].

According to FT-IR analysis, on the SCS surface through the sulfonation process, $-\mathrm{SO}_{3}$ groups were formed, which were concentrated with hydroxyl, carboxyl and carbonyl. Accordingly, depending on the functional groups available on the SCS surface, the adsorption mechanism of $\mathrm{MB}$ can be activated for various interactions. For example, electrostatic attraction between positively charged $\mathrm{MB}$ ions in aqueous solution and negatively charged functional groups on the SCS surface, and hydrogen bonding interactions between the surface hydrogen bonds of functional groups available on the SCS surface and the atoms of MB (Fig. 4).

In addition, according to the analysis of FT-IR, SCS has a structure that can be easily adsorbed to cations. The possible binding of the functional group to the MB on the surface of the SCS would be as follows.
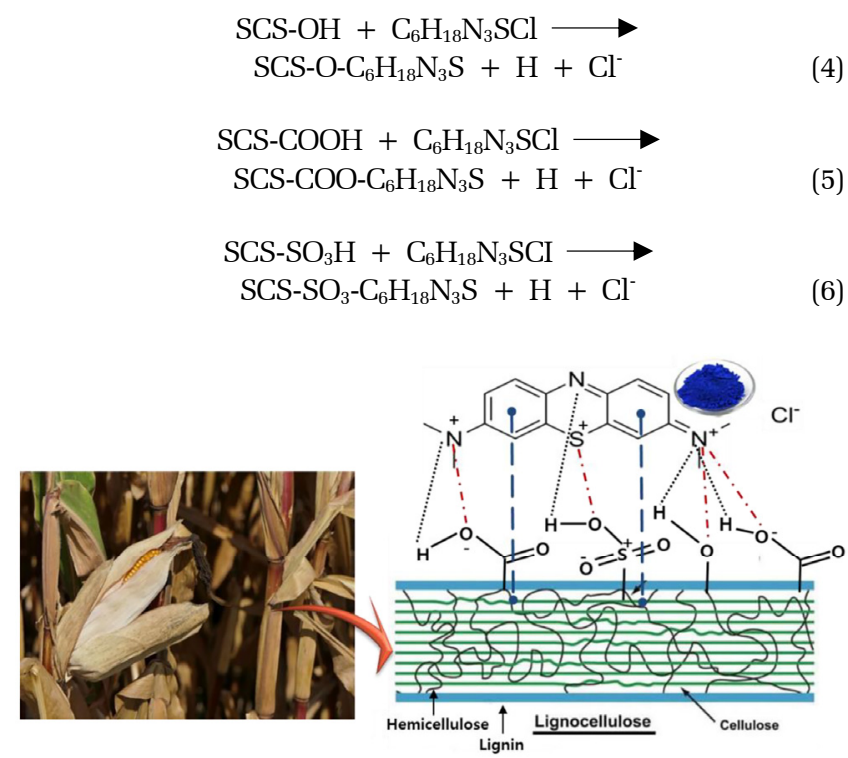

Fig. 4. Possible adsorption mechanism of ligno-cellulose derived SCS with sulfonation.
Factors that can change the adsorption efficiency of ions include functional groups, the amount of charge of ions, differences in ion radius and activity, concentration conditions, and $\mathrm{pH}$ [5]. Another factor is the characteristics of the adsorbent. The smaller the amount of ion exchange of the adsorbent, the more limited the amount that can be adsorbed, so the adsorption efficiency may decrease [18, 22]. The ion exchange capacity of SCS was measured higher than that of CS, indicating that the sulfonation of CS actually increased the ion exchange capacity. Jawad et al. [11] suggested four possible models of the interaction between $\mathrm{MB}$ and sulfonated adsorbents, which were electrostatic interactions, hydrogen bridge formation, electron donor-acceptor relationships, and $\pi-\pi$ electron dispersing forces. However, Heidarinejad et al. [40] emphasized that the MB adsorption mechanism on activated carbon is not fully controlled by electrostatic interactions, as evidenced by the positive effect of ionic strength on increasing adsorption capacity. The change in ionic strength generally occurs due to the presence of intermolecular forces between the adsorbent molecules and the diffusion bilayer compression of the adsorbent surface. Reffas et al. [41] reported that showing the adsorption of $\mathrm{MB}$ on the surface of ligno-cellulose based adsorbents is determined by the presence of $\pi-\pi$ interactions between the base sites on the carbon surface and MB molecules. Another pathway to promote the surface function of carbon is to form composites by chemical activation using chemicals containing the desired functional groups. Robati et al. [42] attached $-\mathrm{NH}$ and $-\mathrm{SH}$ functional groups to the surface through the reaction of cysteamine and the carboxyl group on the surface of the nano-carbon. Que et al. [43] coated the $-\mathrm{SO}_{3}$ group of sodium dodecyl sulfate on the surface of biochar to increase MB adsorption capacity. These results of modifying the adsorbent using chemicals to produce the desired functional group increased the adsorption capacity of MB. In conclusion, sulfonation improved the number of carboxyl groupsand increased the porosity and the surface area of carbon. In the adsorption process of $\mathrm{MB}$ adsorption using SCS in aqueous solution, the sulfone group expanded the form of the adsorbent and increased the exposure of anions to the surface. As a result, the adsorption efficiency of $\mathrm{MB}$, a cationic dye, to SCS was improved. However, according 
to the literature, if the degree of sulfonation is too high, the hydration shell induced by the sulfonic acid group acts as a barrier, preventing the sulfonated adsorbent and the cationic group from accessing each other. This can reduce the adsorption efficiency. Therefore, it is necessary to optimize the degree of sulfonation of the adsorbent.

\subsection{Thermodynamic Interpretation}

In the adsorption process, the reaction temperature affects all potential ion exchange materials as well as the solubility products of metal ions, which can determine the rate of adsorption [4]. The solubility of metal ions affects adsorption efficiency because it may induce ion exchange between the metal ions contained in the aqueous solution and the surface of the adsorbent [27]. The effect of temperature on adsorption efficiency in aqueous solution was investigated, and the results are shown in Table 4 and Fig. S5. According to thermodynamic analysis, adsorption of MB onto SCS in aqueous solution was a spontaneous process, endothermic reaction and corresponds to a physical process.

According to previous studies, opinions on exothermic and endothermic reactions for the adsorption process of harmful substances in aqueous solutions using biomass differ depending on the biomass used as an adsorbent. Several researchers have reported that the bio-adsorption process is an exothermic reaction and is inversely proportional to temperature. Lasheen et al. [44] reported that the adsorption of $\mathrm{Cd}(\mathrm{II})$ using the modified orange peel decreased from $80.13 \%$ to $74.32 \%$ as the temperature increased from $30^{\circ} \mathrm{C}$ to $60^{\circ} \mathrm{C}$, which was attributed to the decrease in the surface activity of the adsorbent. As a result of adsorption of $\mathrm{Zn}(\mathrm{II})$, Cd(II) and Mn(II) using corn stalks in a similar trend, as the temperature increased from $25^{\circ} \mathrm{C}$ to $45^{\circ} \mathrm{C}$, the adsorption efficiency of $\mathrm{Zn}(\mathrm{II})$ was from $52 \%$ to $28 \%$, Cd(II) decreased from $34 \%$ to $16 \%$, and $\mathrm{Mn}$ (II) decreased from $39 \%$ to $13 \%$. The cause of this decrease in adsorption efficiency was explained by the tendency of damage to the active adsorption site of the adsorbent or increasing the number of metal ions discharged from the adsorbent surface to the solution [28]. On the contrary, there are reports of many researchers that the number of available active sites increases as the temperature increases, and the adsorption efficiency increases due to the decrease in the thickness of the boundary layer surrounding the adsorbent [27]. However, many researchers agree without disagreement that too high temperatures can lead to physical damage of bio-adsorbents. For this reason, most experiments using bio-adsorbents are carried out at room temperature. If the reaction temperature is too high, the physical properties of the adsorbent may be denatured, so it is necessary to avoid temperatures above $50^{\circ} \mathrm{C}$.

Table 4. Thermodynamic Parameters for Adsorption of MB onto SCS

\begin{tabular}{|c|c|c|c|}
\hline \multirow{2}{*}{$\begin{array}{c}\text { Temperature } \\
\text { (K) }\end{array}$} & \multicolumn{3}{|c|}{ Thermodynamic $\left[\Delta G^{0}=\Delta H^{0}-T \Delta S^{0}\right]$} \\
\hline & $\triangle G^{\circ}(\mathrm{kJ} / \mathrm{mol})$ & $\triangle \mathrm{H}(\mathrm{kJ} / \mathrm{mol})$ & $\triangle \mathrm{S}(\mathrm{J} / \mathrm{mol} \cdot \mathrm{K})$ \\
\hline 298 & -12.78 & \multirow{4}{*}{12.36} & \multirow{4}{*}{428.74} \\
\hline 303 & -12.99 & & \\
\hline 313 & -13.42 & & \\
\hline 323 & -13.85 & & \\
\hline
\end{tabular}

\section{Conclusions}

This study attempted to remove the cationic dye $\mathrm{MB}$ from aqueous

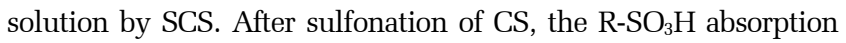
peak, carboxylic groups and $\mathrm{OH}$-group peaks were large on the surface of the adsorbent, and the surface area, pore diameter and ion exchange capacity were remarkably increased. As a result of adsorption kinetics and isothermal adsorption experiments, adsorption of MB to SCS was suitable for pseudo-2nd-order and Langmuir, and the maximum adsorption capacity of Langmuir was 504.3 $\mathrm{mg} / \mathrm{g}$. Finally, the adsorption of MB to the SCS was an endothermic reaction, and the adsorption efficiency improved as the temperature increased, and it was closer to physical adsorption than chemical adsorption. SCS showed excellent adsorption capacity of MB in aqueous solution. However, the powder of SCS is suitable for batch-testing, but it is considered that proper encapsulation is necessary for the convenience of use and prevention of mass loss in order to be applied to the field.

\section{Acknowledgment}

This study was supported by the National Research Foundation of Korea(NRF) grant funded by the Korea government (MSIT) (No.2021R111A3059243)

\section{Author Contributions}

H.J.C. (Prof. Ph.D) performed conceptualization, methodology, data curation, writing - original draft, visualization, investigation, software, validation, writing review \& editing.

\section{References}

1. Choi HJ, Yu SW. Biosorption of methylene blue from aqueous solution by agricultural bioadsorbent corncob. Environ. Eng. Res. 2019;24(1):99-106.

2. Li Y, Xiao H, Pan Y, Wang L. Novel composite adsorbent consisting of dissolved cellulose fiber/microfibrillated cellulose for dyr removal from aqueous solution. ACS Sustain. Chem. Eng. 2018;6:6994-7002.

3. Kumari S, Chauhan GS, Ahn JH. Novel cellulose nanowhiskers-based polyurethane foam for rapid and persistent removal of methylene blue from its aqueous solutions. Chem. Eng. J. 2016;304:728-736.

4. Dai Y, Sun Q, Wang W, et al. Utilization of agricultural waste as adsorbent for the removal of contminants: A review. Chemosphere 2018;211:235-253.

5. Santoso E, Ediati R, Kusumawati Y, Bahruji H, Sulistiono DO, Prasetyoko D. Review on recent advances of carbon based adsorbent for methylene blue removal from waste water. Mater. Today Chem. 2020;16:100233.

6. Aruna, Bagotia N, Sharma AK, Kumar S. A review on modified sugarcane bagasse biosorbent for removal of dyes. Chemosphere 
2021;268:129309.

7. Manna S, Roy D, Saha P, Gopakumar D, Thomas S. Rapid methylene blue adsorption using modified lignocellulosic materials. Process Saf. Environ. Process. 2017;107:346-356.

8. Jawad AH, Razuan R, Appaturi JN, Wilson LD. Adsorption and mechanism study for methylene blue dye removal with carbonized watermelon (Citrullus lanatus) rind prepared via one-step liquid phase $\mathrm{H}_{2} \mathrm{SO}_{4}$ activation. Surf. Interfaces. 2019;16:76-84.

9. Zhang J, Koubaa A, Xing D, et al. Conversion of lignocellulose into biochar and furfural through boron complexation and esterification reactions. Bioresour. Technol. 2020;312:123586.

10. Jawad AH, Rashid RA, Ishak MAM, Wilson LD. Adsorption of methylene blue onto activated carbon developed from biomass waste by $\mathrm{H}_{2} \mathrm{SO}_{4}$ activation: kinetic, equilibrium and thermodynamic studies. Desalin. Water Treat. 2016;57:25194-25206.

11. Zhu S, Xu J, Kuang Y, et al. Lignin-derived sulfonated porous carbon from cornstalk for efficient and selective removal of cationic dyes. Ind. Crop Prod. 2021;159:113071.

12. Roy R, Sajjadur Rahman MD, Raynie DE. Recent advances of greener pretreatment technologies of lignocellulose. Current Res. Green Sustain.Chem. 2020;3:100035.

13. Supanchaiyamat N, Jetsrisuparb K, Knijneburg JTN, Tsang DCW, Hunt AJ. Lignin materials for adsorption: current trend, perspectives and opportunities. Bioresour. Technol. 2019;272: 570-581.

14. Li X, Lu X, Liang M, et al. Conversion of waste lignocellulose to furfural using sulfonated carbon microspheres as catalyst. Waste Manag. 2020; 108:119-126.

15. Elangovan R, Philip L, Chandraraj K. Biosorption of chromium species by aquatic weeds: kinetics and mechanism studies. J. Hazard. Mater. 2018;152:100-112.

16. Choi HJ. Assessment of the adsorption kinetics, equilibrium, and thermodynamic for $\mathrm{Pb}$ (II) removal using a low-cost hybrid biowaste adsorbent, eggshell/coffee ground/sericite. Water Environ. Res. 2019;91:1600-1612.

17. Hagesteijn KFL, Jiang S, Ladewig BP. A review of the synthesis and characterization of anion exchange membranes. J. Mater. Sci. 2018;53:11131-11150.

18. Barylak M, Cendrowski K, Mijowska E. Application of carbonized metal-organic framework as efficient adsorbent of cationic dye. Ind. Eng. Chem. Res. 2018;57:4867-4879.

19. Furtmair M, Timm J, Marschall R. Sulfonation of porous materials and their proton conductivity. Micropor. Mesopor. Mat. 2021;312:110745.

20. Dora S, Bhaskar T, Singh R, Naik DV, Adhikari DK. Effective catalytic conversion of cellulose into high yields of methyl glucosides over sulfonated carbon based catalyst. Bioresour. Technol. 2012;120:318-321.

21. Feng Q, Cheng H, Chen F, Zhou X, Wang P, Xie Y. Investigation of cationic dye adsorption from water onto acetic acid lignin. J. Wood Chem. Technol. 2015;36:173-181.

22. Sabar S, Abdul Aziz H, Yusof NH, et al. Preparation of sulfonated chitosan for enhanced adsorption of methylene blue from aqueous solution. React. Funct. Polym. 2020;151:104584.

23. Boota R, Bhatti HN, Hanif MA. Removal of $\mathrm{Cu}(\mathrm{II})$ and $\mathrm{Zn}$ (II) using lignocellulosic fiber derived from Citrus reticulata
(Kinnow) waste biomass. Sep.Purif. Technol. 2009;44:4000-4022. 24. Benadjemia M, Millière L, Reinert L, Benderdouche N, Duclaux L. Preparation, characterization and methylene blue adsorption of phosphoric acid activated carbons from globe artichoke leaves. Fuel Process. Technol. 2011;92:1203-1212.

25. Choi HJ. Assessment of the adsorption kinetics, equilibrium and thermodynamic for $\mathrm{Pb}(\mathrm{II})$ removal using a hybrid adsorbent, eggshell and sericite, in aqueous solution. Water Sci. Technol. 2019;79(10):1922-1933.

26. Jawad AH, Mamat NFH, Abdullah MF, Ismail,K. Adsorption of methylene blue onto acid-treated mango peels: kinetic, equilibrium and thermodynamic. Desalin. Water Treat. 2017;59:210-219.

27. Li J, Li H, Yuan Z, et al. Role of sulfonation in lignin-based material for adsorption removal of cationic dyes. Int. J. Biol. Macromol. 2019;135:1171-1181.

28. Osman HE, Badwy RK, Ahmad HK. Usage of some agricultural by-products in the removal of some heavy metals from industrial wastewater. J. Phytol. Res. 2010;2:51-62.

29. Weijue GAO, Inwood JPW, Fatehi P. Sulfonation of hydroxy methylated lignin and its application. J. Bioresour. Bioprod. 2019;4(2):80-88.

30. Lee SY, Choi HJ. Persimmon leaf bio-waste for adsorptive removal of heavy metals from aqueous solution. J. Environ. Manage. 2018:209:382-392.

31. Rodrigues AE, Silva CM. What's wrong with lagergreen pseudo first order model for adsorption kinetics? Chem. Eng. J. 2016;306:1138-1142.

32. Yu SW, Choi HJ. Application of hybrid bead, persimmon leaf and chitosan for the treatment of aqueous solution contaminated with toxic heavy metal ions. Water Sci. Technol. 2018;78(4): 837-847.

33. Choi HJ, Yu SW, Kim KH. Efficient use of Mg-modified zeolite in the treatment of aqueous solution contaminated with heavy metal toxic ions. J. Taiwan Inst. Chem. Eng. 2016;63:482-489.

34. Ma J, Yu F, Zhou L, et al. Enhanced adsorptive removal of methyl orange and methylene blue from aqueous solution by alkali-activated multiwalled carbon nanotubes. ACS Appl. Mater. Interfaces. 2012;4:5749-5760.

35. Yang J, Qiu K. Preparation of activated carbons from walnut shells via vacuum chemical activation and their application for methylene blue removal. Chem. Eng. J. 2010;165:209-217.

36. Salazar-Rabage JJ, Leyva-Ramos R, Rivera-Utrilla J, OcampoPerez R, Cerino-Cordova FJ. Biosorption mechanism of methylene blue from aqueous solution onto white pine (Pinus durangensis) sawdust: Effect of operating conditions. Sustain. Environ. Res. 2017;7:32-40.

37. Zhang S, Wang Z, Zhang Y, Pan H, Tao L. Adsorption of methylene blue on organosolv lignin from rice straw. Procedia Environ. Sci. 2016;31:3-11.

38. Uddin MT, Islam MA, Mahmud S, Rukanuzzaman M. Adsorptive removal of methylene blue by tea waste. J. Hazard. Mater. 2009;164:53-60.

39. Ämmälä A, Laitinen O, Sirviö JA, Liimatainen H. Key role of mild sulfonation of pine sawdust in the production of lignin containing microfibrillated cellulose by ultrafine wet grinding. Ind. Crop. Prod. 2019;140:111664.

40. Heidarinejad Z, Rahmanian O, Fazlzadeh M, Heidari M. 
Enhancement of methylene blue adsorption onto activated carbon prepared from data press cake by low frequency ultrsound. J. Mol. Liq. 2018;264:591-599.

41. Reffas A, Bernardet V, David B, et al. Carbons prepared from coffee grounds by $\mathrm{H}_{3} \mathrm{PO} 4$ activation: characterization and adsorption of methylene blue and Nylosan Red N-2RBL. J. Hazard. Mater. 2010;175:779-788.

42. Robati D, Bagheriyan S, Rajabi M, Moradi O, Ahmadi Peyghan A. Effect of electrostatic interaction on the methylene blue and methyl orange adsorption by the pristine and functionalized carbon nanotubes. Physica E. 2010;83:1-6.

43. Que W, Jiang L, Wang C, et al. Influence of sodium dodecyl sulfate coating on adsorption of methylene blue by biochar from aqueous solution. J. Environ. Sci. 2018;70:166-174.

44. Lasheen MR, Ammar NS, Ibrahim HS. Adsorption/desorption of $\mathrm{Cd}(\mathrm{II}), \mathrm{Cu}(\mathrm{II})$ and $\mathrm{Pb}(\mathrm{II})$ using chemically modified orange peel: equilibrium and kinetic studies. Solid State Sci. 2012;14:202-210. 